\title{
ChemComm
}

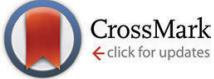

Cite this: Chem. Commun., 2015, 51, 12036

Received 12th February 2015 Accepted 15th June 2015

DOI: $10.1039 / \mathrm{c5cc01344e}$

www.rsc.org/chemcomm

\section{Tailoring flavins for visible light photocatalysis: organocatalytic [2+2] cycloadditions mediated by a flavin derivative and visible light $\dagger$}

\author{
Viktor Mojr, ${ }^{a}$ Eva Svobodová, ${ }^{a}$ Karolína Straková, ${ }^{a}$ Tomáš Neveselý, ${ }^{a}$ \\ Josef Chudoba, ${ }^{\mathrm{b}}$ Hana Dvořákováb and Radek Cibulka*a
}

\begin{abstract}
A new application of flavin derivatives in visible light photocatalysis was found. 1-Butyl-7,8-dimethoxy-3-methylalloxazine, when irradiated by visible light, was shown to allow an efficient cyclobutane ring formation via an intramolecular [2+2] cycloaddition of both styrene dienes, considered as electron-rich substrates, and electron-poor bis(arylenones), presumably proceeding via an energy transfer mechanism.
\end{abstract}

The rapid development of visible light photocatalysis that has occurred in the past decade has stimulated a renaissance of organic photochemistry. ${ }^{1,2}$ Replacement of high-intensity UV light with visible light in combination with suitable photocatalysts/ sensitisers absorbing in the appropriate region has made photochemistry available for most laboratories ${ }^{3}$ as it can be performed in common vessels made from borosilicate glass and using conventional light sources, including the current light emitting diodes (LEDs). ${ }^{4}$ Photoexcitation, in general, allows several chemical transformations that are not accessible by thermal reactions. ${ }^{5,6}$ Use of visible light even improves classical photochemical methodologies by avoiding side reactions of functionalities sensitive to UV light.

The [2+2] cycloaddition of alkenes, producing cyclobutane derivatives, represents a typical challenge for photochemistry as corresponding thermal procedures and four-membered ring cyclisations are disfavoured. ${ }^{7}$ Conventional synthetic methods for $[2+2]$ photocycloadditions usually require high-intensity UV light, ${ }^{8}$ but recently, new procedures based on visible light photocatalysis have also appeared in this important area. Yoon reported radical $[2+2]$ cycloadditions using a $\mathrm{Ru}(\mathrm{bpy})_{3}{ }^{2+}$ photocatalyst, which occur after irradiation with visible light in the presence of a sacrificial reducing or oxidising agent in the case of either electron-poor (arylenones) or electron-rich substrates

\footnotetext{
${ }^{a}$ Department of Organic Chemistry, University of Chemistry and Technology, Prague, Technická 5, 16628 Prague, Czech Republic.E-mail: cibulkar@vscht.cz

${ }^{b}$ Central Laboratories, University of Chemistry and Technology, Prague, Technická 5, 16628 Prague, Czech Republic

$\dagger$ Electronic supplementary information (ESI) available: Experimental procedures, characterization data and copies of NMR and UV-VIS spectra. See DOI: 10.1039/c5cc01344e
}

(styrenes), respectively. ${ }^{9,10}$ Nicewicz described [2+2] cycloadditions of electron-rich styrenes with tris-(4-methoxyphenyl)pyrylium tetrafluoroborate working in the excited state as a single electron oxidant; ${ }^{11 a}$ Zeitler showed reductive cyclization of arylenones to take place with Eosin $\mathrm{Y}^{11 b}$ In contrast to electron transfer processes, [2+2] photocycloadditions involving energy transfer are applicable across a broad substrate scope as they are not limited by the electrochemical properties of the substrates. Nevertheless, such processes utilising visible light are still very rare; an iridium(III) polypyridyl complex $\left(E_{\mathrm{T}}=255 \mathrm{~kJ} \mathrm{~mol}^{-1}\right)$ providing an intramolecular $[2+2]$ cycloaddition of substituted styrenes ${ }^{12}$ and very recent systems, based on a thioxanthone dye $\left(E_{\mathrm{T}}=264 \mathrm{~kJ} \mathrm{~mol}^{-1}\right)$, designed by Bach ${ }^{13}$ and Sivaguru ${ }^{14}$ for stereoselective [2+2] cycloadditions of a specific group of substrates are the only examples.

Noble metal complexes still dominate as photoactive species in visible light photocatalysis. ${ }^{1}$ Because of the price of the dye, as well as environmental aspects representing significant issues, looking for a new, simple photoactive organocatalyst and its application in photocatalysis represents an important goal. ${ }^{2}$ One of the most prominent natural chromophores is represented by flavin cofactors ${ }^{15}$ (Fig. 1), which are involved in several light-dependent processes, for example, in light generation by bacterial luciferase, ${ }^{16}$ in plant phototropism ${ }^{17}$ and in the activity of photolyases for the cleavage of cyclobutanepyrimidine dimers to repair DNA damage. ${ }^{18}$ Due to interesting photochemical properties, flavins (e.g., riboflavin tetraacetate 1) have been tested in photocatalysis; ${ }^{19,20}$ nevertheless, their applications, except of photolyase models, ${ }^{21}$ are still limited to photooxidations of benzylic derivatives, amines and sulfides.

Our idea of applying flavins to sensitised visible light [2+2] cycloadditions led us to consider their triplet energy, which is too low in the case of blue light-absorbing isoalloxazines $\left(\lambda_{\max }=\right.$ $450 \mathrm{~nm} ; E_{\mathrm{T}}=209 \mathrm{~kJ} \mathrm{~mol}^{-1}$ for riboflavin ${ }^{22}$ ) to excite substituted styrenes usually used as substrates for this reaction $\left(E_{\mathrm{T}}=\right.$ 249 and $259 \mathrm{~kJ} \mathrm{~mol}^{-1}$ for $\beta$-methylstyrene ${ }^{23 a}$ and 1-phenylbut2-en-1-one ${ }^{23 b}$, respectively). Indeed, our attempt to use $\mathbf{1}$ as a photocatalyst for 3a cycloaddition did not lead to the cyclobutane product. Therefore, we turned our attention to isomeric alloxazines (Fig. 1) absorbing light on the border of the visible region with triplet 
<smiles>[R]n1c2nc(=O)[nH]c(=O)c-2nc2cc(C)c(C)cc21</smiles>

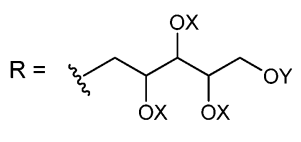

Vitamin B2 (Riboflavin): $X=Y=H$

Cofactors: $\quad \mathrm{FMN}: \quad \mathrm{X}=\mathrm{H}, \mathrm{Y}=\mathrm{PO}_{3}^{-}$

FAD: $X=H, Y=A D P$

Photocatalyst: 1 (RFTA): $X=Y=A C\left(E^{0-0}=240 \mathrm{~kJ} \mathrm{~mol}^{-1}\right)$<smiles>CCOc1cc2nc3c(=O)n(C)c(=O)n(Cc4ccccc4)c3nc2cc1OC</smiles>

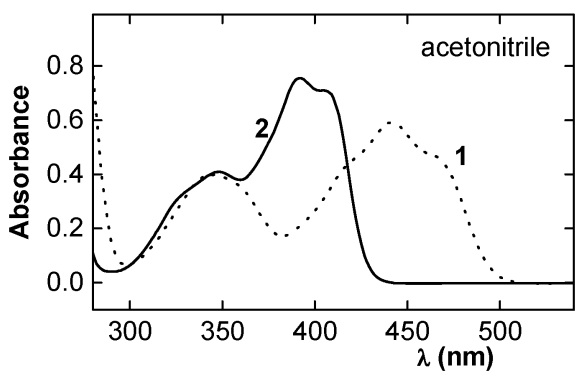

Fig. 1 Flavins involved in natural and artificial photochemical processes, design of photocatalyst $\mathbf{2}$ and the UV-VIS spectra of $\mathbf{1}$ and $\mathbf{2}\left(c=5 \times 10^{-5} \mathrm{~mol} \mathrm{~L}^{-1}\right)$.

energies expected to be above those of isoalloxazines $\left(E_{\mathrm{T}}=\right.$ $245 \mathrm{~kJ} \mathrm{~mol}^{-1}$ for 1,3,7,8-tetramethyl-alloxazine). ${ }^{24}$ Moreover, alloxazines are known to exhibit high intersystem crossing (ISC) yields (e.g. $\Phi_{\mathrm{ISC}}=0.71$ for 7,8-dimethylalloxazine in acetonitrile). ${ }^{24 b, 25}$ For our purpose, we tuned the alloxazine structure by introducing methoxy groups to the benzene ring to adjust the absorption maximum to approximately $400 \mathrm{~nm}$ and added a butyl chain on the $\mathrm{N}(1)$ nitrogen to provide sufficient solubility for the catalyst (for the synthesis of 2, see the ESI $\dagger$ ).

To our delight, irradiation of a solution of diene (E)-3a in the presence of $2.5 \mathrm{~mol} \%$ of 2 with a $400 \mathrm{~nm}$ LED led to the formation of the [2+2] cycloadduct $\mathbf{4 a}$ within a short time (Table 1 ). The conversion to the [2+2] cycloadduct after 10 minutes of irradiation did not differ in most types of solvents (entries 1-7). Nevertheless, in alcohols (entries 8 and 9) and mainly in acetonitrile (entry 10), it still increased. Additionally, we detected the formation of (Z)-3a, providing evidence that a triplet state $E / Z$ photoisomerisation of the styrene double bond occurs. The rate of isomerisation is faster than the rate of cycloaddition, as demonstrated by the composition of the reaction mixtures in acetonitrile after 1 and 10 minutes of irradiation ( $c f$. entries 10 and 12, see the ESI $\dagger$ for the kinetic profile). It is noteworthy that irradiation of (Z)-3a led to a mixture of the same composition as that of $(E)-3 \mathbf{a}(c f$. entries 10 and 11); the cycloadduct of the same relative configuration was formed as the major product, regardless of the configuration of the starting styrene.

Flavins including alloxazines are known to sensitise the formation of singlet oxygen..$^{20 a, 25}$ Therefore, standard experiments were performed in Schlenk tubes under an argon atmosphere, not allowing singlet oxygen chemistry to proceed. Nevertheless, no side products were observed after irradiation under an air atmosphere,
Table 1 [2+2] Photocycloaddition of 3a mediated by $\mathbf{2}$ and visible light performed on an analytical scale ${ }^{a}$

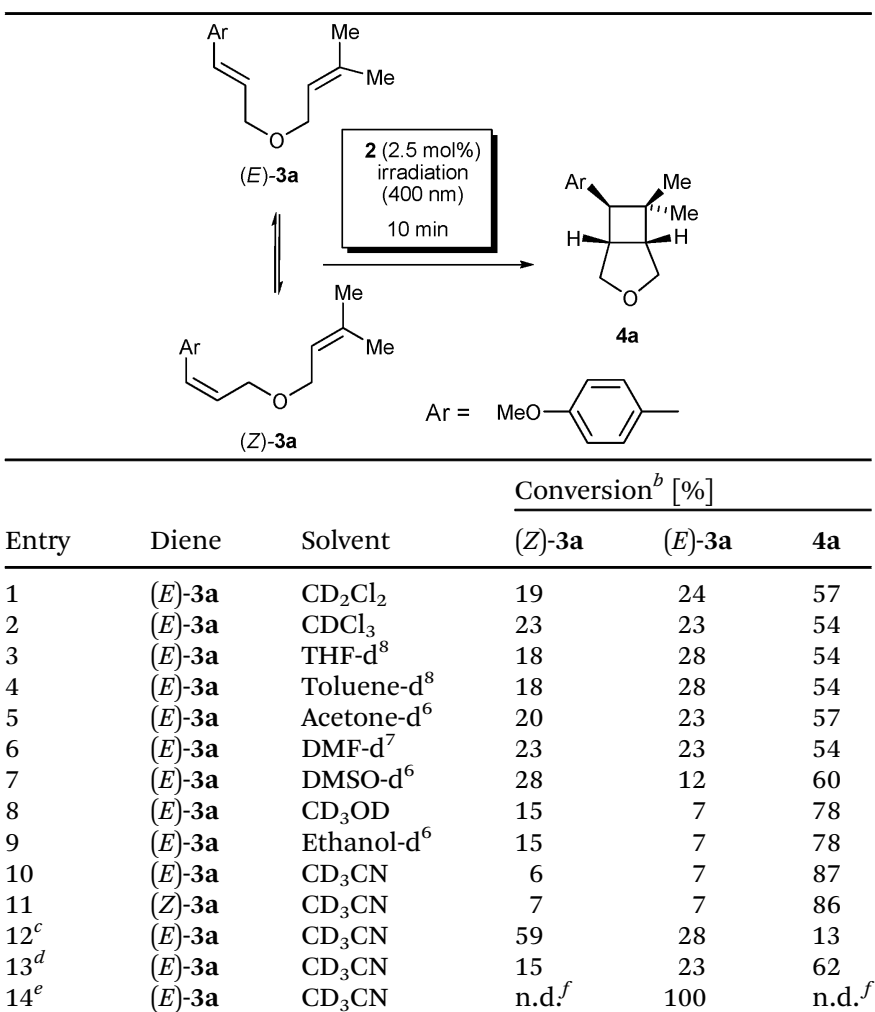

${ }^{a}$ Reaction was performed in a Schlenk tube in $1 \mathrm{~mL}$ of solvent under an argon atmosphere; $c(2)=5 \times 10^{-4} \mathrm{~mol} \mathrm{~L}^{-1}, c(3 \mathbf{a})=2 \times 10^{-2} \mathrm{~mol} \mathrm{~L}^{-1}$. ${ }^{b}$ Relative conversion determined using ${ }^{1} \mathrm{H}$ NMR; total conversion was proved not to drop under $95 \%$ using a calibrated internal standard. Reaction time: 1 min. ${ }^{d}$ Under air. ${ }^{e}$ With $\mathbf{1}$ as the catalyst. ${ }^{f}$ Not detected.

showing that the reaction could be performed simply in a flask without the exclusion of oxygen. Of course, it took place more slowly under air as the excited catalyst was partially quenched by oxygen (cf. entries 10 and 13). As expected, with RFTA, neither isomerization nor cycloaddition occurred even under optimized conditions (entry 14). In acetonitrile, several blank experiments were performed to exclude spontaneous formation of the cycloadduct, but cycloaddition or isomerisation of 3a did not occur without light or a photocatalyst. Our effort to study the substrate scope led us to perform blank experiments with dienes 3, 5, 7, 9 and 11, which did not form a cycloadduct in the absence of 2 . The only exception was the 4-nitroderivative $3 \mathbf{e}\left(\mathrm{R}=\mathrm{NO}_{2}\right.$, in Table 2), which formed a cyclobutane spontaneously after irradiation as it has low but still sufficient absorption at $400 \mathrm{~nm}$ (see the ESI†).

A substrate scope investigation performed on a semipreparative scale under optimised conditions showed our photocatalytic system based on 2 to be a versatile tool for intramolecular [2+2] cycloadditions of various types of dienes (Table 2), including styrenes 3 with both electron-donating and electron-withdrawing substituents, symmetrical and non-symmetrical bis(styrenes) 5, 7 and $\mathbf{9}$, and, interestingly, bis(arylenones) 11, which belong among the electron-poor substrates that are usually the subject of visible light photocycloadditions by a reductive radical pathway taking place in the presence of a Lewis acid (lithium salt) only even with 
Table 2 Substrate scope investigation for [2+2] photocycloadditions mediated by 2 and visible light $^{a}$

Entry Substrate

strong reductants such as excited $\mathrm{Ru}(\mathrm{bpy})_{3}$ or Eosin $\mathrm{Y} . .^{9,10,11 b}$ In the $[2+2]$ photocycloaddition mediated by 2 , there is indirect evidence that it occurs presumably via an energy transfer mechanism (Scheme 1) which could be allowed (despite the fact that it seems to be slightly endothermic ${ }^{26}$ ) by high $\Phi_{\text {ISC }}$ of 2 and/or by nonvertical energy transfer: ${ }^{27}$ (i) substrates 3c, 3d, 9 and $\mathbf{1 1}$ are too electron-poor to be oxidised with excited alloxazines (see the $\mathrm{ESI}^{\dagger}$ ), (ii) triplet state $E / Z$-photoisomerization occurs after irradiation of 1-phenylpropene, 1-( $p$-methoxyphenyl)propene as well as 1-(4-methoxyphenyl)but-2-en-1-one in the presence of alloxazine 2 (see the ESI $\dagger$ ), (iii) irradiation of $(Z)$-3a led to a mixture of the same composition as that of $(E)-3 \mathbf{a}$ and (iv) cyclization of $(Z, Z)$-11a gave almost the same mixture of cyclobutane products preferentially with the cis configuration of arylcarbonyl groups as we observed for $(E, E)$-11a ( $c f$. entries 10 and 13). On the other hand, the reductive mechanism cannot be excluded for strongly electron-poor 11c.

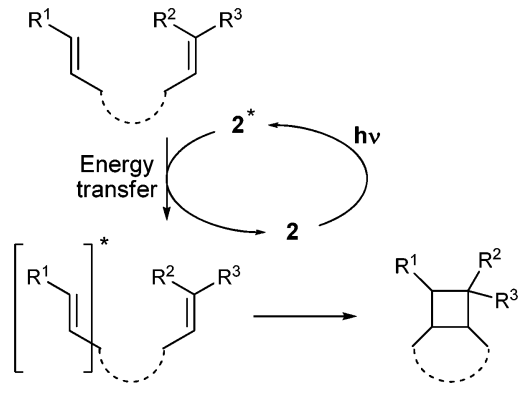

Scheme 1 Proposed mechanism of [2+2] photocycloaddition mediated by 2 and visible light.

It is noteworthy that quantitative conversions were achieved in all cases and that cycloadditions with electron-rich styrenes were faster than with the other substrates. Irradiation of 1-phenylpropene and 1-( $p$-methoxyphenyl)propene led to only photoisomerisation (see $\mathrm{ESI} \dagger)$, most likely because of the extremely short lifetime ${ }^{23}$ of the triplet state of styrenes, disfavouring intermolecular cyclisation. Concerning stereochemistry, our results correspond to those from photocatalytic radical processes: ${ }^{9,10}$ (i) exo diastereoisomers were formed as major products with excellent diastereoselectivity for $\mathbf{3}$, and (ii) cycloadditions of 5, 7, 9 and 11 yielded predominantly products with cis configurations of aryl and arylcarbonyl substituents.

In summary, we demonstrated the first application of a flavin derivative for photocatalytic $\mathrm{C}-\mathrm{C}$ bond formation thus opening a completely new application area for flavin photocatalysts, which have been used solely in photooxidations. The use of alloxazine instead of isoalloxazine allowed us to perform an intramolecular visible light [2+2] photocycloaddition, which is still considered the domain of noble metal complex photocatalysts. Photocycloaddition with organocatalyst 2 was shown to take place with a broad spectrum of dienes. Thanks to its versatility and its utilisation of a combination of the photoactive organocatalyst and visible light, the system with flavin 2 distinguishes itself from those already published for visible light $[2+2]$ photocycloadditions. Some other flavin derivatives are expected to be able to promote similar reactivity, which offers the possibility for further enhancement of the photocatalytic system presented.

This project was supported by the Czech Science Foundation (Grant No. 14-09190S), and the German National Science Foundation (GRK 1626 "Chemical Photocatalysis").

\section{Notes and references}

1 (a) D. M. Schultz and T. P. Yoon, Science, 2014, 343, 985; (b) Y. Xi, H. Yi and A. Lei, Org. Biomol. Chem., 2013, 11, 2387; (c) M. Reckenthäler and A. G. Griesbeck, Adv. Synth. Catal., 2013, 355, 2727; (d) C. K. Prier, D. A. Rankic and D. W. C. MacMillan, Chem. Rev., 2013, 113, 5322; (e) J. M. R. Narayanam and C. R. J. Stephenson, Chem. Soc. Rev., 2011, 40, 102.

2 (a) D. Ravelli, M. Fagnoni and A. Albini, Chem. Soc. Rev., 2013, 42, 97; (b) D. A. Nicewicz and T. M. Nguyen, ACS Catal., 2013, 4, 355.

3 C.-L. Ciana and C. G. Bochet, Chimia, 2007, 61, 650.

4 P. Von Dollen, S. Pimputkar and J. S. Speck, Angew. Chem., Int. Ed., 2014, 53, 13978.

5 N. J. Turro, V. Ramamurthy and J. C. Scaiano, Modern Molecular Photochemistry of Organic Molecules, University Science Books, Sausalito, CA, 2010. 
6 (a) T. Bach and J. P. Hehn, Angew. Chem., Int. Ed., 2011, 50, 1000; (b) N. Hoffmann, Chem. Rev., 2008, 108, 1052.

7 (a) E. Lee-Ruff and G. Mladenova, Chem. Rev., 2003, 103, 1449; (b) R. Hoffmann and R. B. Woodward, J. Am. Chem. Soc., 1965, 87, 2046.

8 J. P. Hehn, C. Müller and T. Bach, in Handbook of Synthetic Photochemistry, ed. A. Albini and M. Fagnoni, Wiley-VCH Verlag GmbH \& Co. KGaA, Weinheim, 2010, pp. 171-215.

9 T. P. Yoon, ACS Catal., 2013, 3, 895.

10 (a) A. E. Hurtley, Z. Lu and T. P. Yoon, Angew. Chem., Int. Ed., 2014, 53, 8991; (b) J. Du, K. L. Skubi, D. M. Schultz and T. P. Yoon, Science, 2014, 344, 392; (c) E. L. Tyson, E. P. Farney and T. P. Yoon, Org. Lett., 2012, 14, 1110; (d) M. A. Ischay, M. S. Ament and T. P. Yoon, Chem. Sci., 2012, 3, 2807; (e) J. Du, L. R. Espelt, I. A. Guzei and T. P. Yoon, Chem. Sci., 2011, 2, 2115; $(f)$ M. A. Ischay, Z. Lu and T. P. Yoon, J. Am. Chem. Soc., 2010, 132, 8572; $(g)$ J. Du and T. P. Yoon, J. Am. Chem. Soc., 2009, 131, 14604; (h) M. A. Ischay, M. E. Anzovino, J. Du and T. P. Yoon, J. Am. Chem. Soc., 2008, 130, 12886.

11 (a) M. Riener and D. A. Nicewicz, Chem. Sci., 2013, 4, 2625; (b) M. Neumann and K. Zeitler, Chem. - Eur. J., 2013, 19, 6950-6955.

12 Z. Lu and T. P. Yoon, Angew. Chem., Int. Ed., 2012, 51, 10329.

13 R. Alonso and T. Bach, Angew. Chem., Int. Ed., 2014, 53, 4368.

14 E. Kumarasamy, R. Raghunathan, S. Jockusch, A. Ugrinov and J. Sivaguru, J. Am. Chem. Soc., 2014, 136, 8729.

15 (a) Flavins, Photochemistry and Photobiology, ed. E. Silva and A. M. Edwards, Royal Society of Chemistry, Cambridge, 2006; (b) P. F. Heelis, Chem. Soc. Rev., 1982, 11, 15.

16 T. O. Baldwin, J. A. Christopher, F. M. Raushel, J. F. Sinclair, M. M. Ziegler, A. J. Fisher and I. Rayment, Curr. Opin. Struct. Biol., 1995, 5, 798.

17 A. Losi and W. Gärtner, Photochem. Photobiol., 2011, 87, 491.

18 A. Sancar, Chem. Rev., 2003, 103, 2203.

19 For reviews on flavin photocatalysis, see: (a) S. Kümmel, R. Cibulka and B. König, in Chemical Photocatalysis, ed. B. König, de Gruyter,
Berlin, 2013, pp. 45-66; (b) G. de Gonzalo and M. W. Fraaije, ChemCatChem, 2013, 5, 403.

20 For recent papers on flavin photocatalysis, see: (a) M. Insińska-Rak and M. Sikorski, Chem. - Eur. J., 2014, 20, 15280; (b) J. Dad'ová, S. Kümmel, C. Feldmeier, J. Cibulková, R. Pažout, J. Maixner, R. M. Gschwind, B. König and R. Cibulka, Chem. - Eur. J., 2013, 19, 1066; (c) B. Muhldorf and R. Wolf, Chem. Commun., 2015, 51, 8425-8428; (d) C. Feldmeier, H. Bartling, K. Magerl and R. M. Gschwind, Angew. Chem., Int. Ed., 2015, 54, 1347-1351.

21 T. Carell and R. Epple, Eur. J. Org. Chem., 1998, 1245.

22 S. L. Murov, I. Carmichael and G. L. Hug, Handbook of Photochemistry, 2nd edn, Taylor \& Francis, 1993.

23 (a) T. Ni, R. A. Caldwell and L. A. Melton, J. Am. Chem. Soc., 1989, 111, 457; (b) R. A. A. U. Ranaweera, T. Scott, Q. Li, S. Rajam, A. Duncan, R. Li, A. Evans, C. Bohne, J. P. Toscano, B. S. Ault and A. D. Gudmundsdottir, J. Phys. Chem. A, 2014, 118, 10433-10447.

24 (a) P.-S. Song and W. E. Kurtin, J. Am. Chem. Soc., 1967, 89, 4248; (b) E. Sikorska, I. V. Khmelinskii, W. Prukała, S. L. Williams, M. Patel, D. R. Worrall, J. L. Bourdelande, J. Koput and M. Sikorski, J. Phys. Chem. A, 2004, 108, 1501-1508.

25 E. Sikorska, M. Sikorski, R. P. Steer, F. Wilkinson and D. R. Worrall, J. Chem. Soc., Faraday Trans., 1998, 94, 2347-2353.

26 There are several examples for endothermic energy transfer between an excited sensitizer and alkene, see: J. J. Snyder, F. P. Tise, R. D. Davis and P. J. Kropp, J. Org. Chem., 1981, 46, 3609-3611; T. Arai, H. Sakuragi and K. Tokumaru, Bull. Chem. Soc. Jpn., 1982, 55, 2204-2207.

27 Excitation of alkene from the ground state to a twisted geometry having energy lower than planar triplet energy (the difference about $32 \mathrm{~kJ} \mathrm{~mol}^{-1}$ is reported ${ }^{23}$ for acyclic styrenes) was shown in many cases, see: E. Garcia-Exposito, R. Gonzalez-Moreno, M. Martin-Vila, E. Muray, J. Rife, J. L. Bourdelande, V. Branchadell and R. M. Ortuno, J. Org. Chem., 2000, 65, 6958-6965 and references cited therein. 